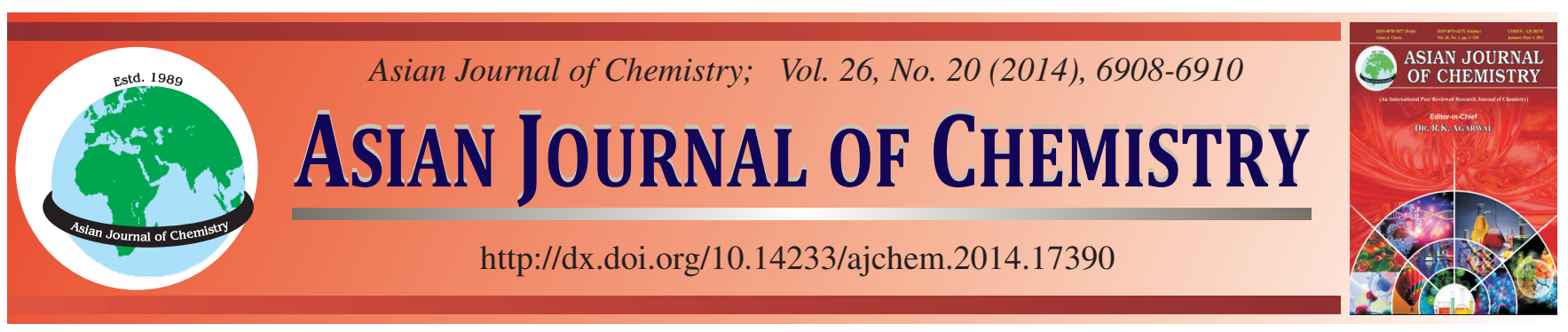

\title{
Bromo-Substituted Salamo-Type Compounds Possessing More Flexible O-Alkyl Chain: Synthesis and Sructural Characterization
}

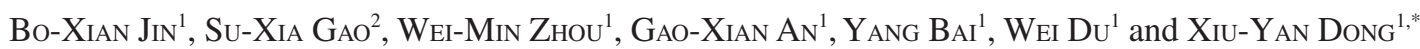

${ }^{1}$ School of Chemical and Biological Engineering, Lanzhou Jiaotong University, Lanzhou 730070, P.R. China

${ }^{2}$ School of Environmental and Municipal Engineering, Lanzhou Jiaotong University, Lanzhou 730070, P.R. China

*Corresponding author: E-mail: dxy568@163.com

Received: 13 February 2014;

Accepted: 5 May 2014;

Published online: 25 September 2014;

AJC-16036

A series of bromo-substituted Salamo-type compounds have been synthesized by the reaction of 5-bromo-2-hydroxybenzaldehyde with 1,7-bis(aminooxy)heptane, 1,8-bis(aminooxy)octane, 1,9-bis(aminooxy)nonane or 1,10-bis(aminooxy)decane in hot ethanol medium, respectively, and characterized by elemental analyses, IR, UV-visible spectra and ${ }^{1} \mathrm{H}$ NMR spectroscopy.

Keywords: Salamo-type bisoxime ligand, Synthesis, Characterization.

\section{INTRODUCTION}

Oxime-type chelate ligands, condensed by oxyammonia and aldehyde or alkone, were widely used as the donor materials in the modern metal-organic coordinating chemistery ${ }^{1}$. Especially, the bisoxime-type compounds have drawn increasing attentions for their diverse structures and broad applications prospects in medicine, catalysis, optoelectronic and magnetism ${ }^{2-5}$. In recent years, the research of the metalorganic complexes with these Salamo-type bisoxime ligands and transition metals have made great progress ${ }^{6-8}$. In order to investigating the structural properties of the bisoxime-type compounds, we have synthesized a serial of bisxiome compounds from 5-bromo-2-hydroxybenzaldehyde and bis(aminooxy)alkane with different long-chain alkane molecules, 4,4'-bibromo-2,2'-[1,7-(heptanediyldioxy)bis(nitrilomethylidyne)]diphenol, 4,4'-bibromo-2,2'-[1,8-(octanediyldioxy)bis(nitrilomethylidyne)]diphenol, 4,4'-bibromo-2,2'[1,9-(nontanediyldioxy)bis(nitrilomethylidyne)]diphenol, 4,4'bibromo-2,2'-[1,10-(decanediyldioxy)bis(nitrilomethylidyne)]diphenol and the characterizations have also been studied.

\section{EXPERIMENTAL}

5-Bromo-2-hydroxy-benzaldehyde ( $\geq 98 \%$ ), 1,7dibromoheptane, 1,8-dibromooctane, 1,9-dibromononane and 1,10-dibromodecane were purchased from Alfa Aesar and used without further purification. The other reagents and solvents were analytical grade reagents from Tianjin Chemical Reagent Factory. C, $\mathrm{H}$ and $\mathrm{N}$ analyses were carried out with a $\mathrm{GmbH}$
VariuoEL V3.00 automatic elemental analyzer. Melting points were measured by the use of a microscopic melting point apparatus made in Beijing Taike Instrument Limited Company. IR spectra were recorded on a VERTEX70 FT-IR spectrophotometer, with samples prepared as $\mathrm{KBr}\left(4000-400 \mathrm{~cm}^{-1}\right)$ pellets. UV-visible absorption spectra were recorded on a Shimadzu UV-2550 spectrometer and the thermometer was uncorrected. ${ }^{1} \mathrm{H}$ NMR spectra were recorded on a Mercury-400BB spectrometer.

General procedure: Synthetic route to Salamo-type bisoxime compounds $\mathbf{H}_{2} \mathbf{L}^{1}-\mathbf{H}_{2} \mathbf{L}^{4}$ are shown in Fig. 1. 1,7-bis(aminooxy)heptanes, 1,8-bis(aminooxy)octane, 1,9-bis(aminooxy)nonane and 1,10-bis(aminooxy)decane were synthesized according to an analogous method reported earlier ${ }^{9-11}$.

Preparation of 4,4'-dibromo-2,2'-[1,7-(heptanediyldioxy)bis (nitrilomethylidyne)]diphenol $\left(\mathbf{H}_{2} \mathbf{L}^{1}\right)$ : To a hot ethanolic solution $(10 \mathrm{~mL})$ of 5-bromo-2-hydroxy-benzaldehyde (201.3 mg, $1 \mathrm{mmol}$ ) was added a hot ethanolic solution (10 mL) of 1,7-bis(aminooxy)heptane $(81.1 \mathrm{mg}, 0.50 \mathrm{mmol})$. After the solution had been stirred at $60{ }^{\circ} \mathrm{C}$ for $6 \mathrm{~h}$, then cooled to room temperature. The white precipitate was filtered and washed successively with ethanol and $n$-hexane, respectively. The product was purified with recrystallization from ethanol/ $n$-hexane (1/4) and dried under vacuum to obtain the compound $\mathbf{H}_{2} \mathbf{L}^{1}$. Yield (\%): 82.7; m.p.: 384-385 K.

Preparation of 4,4'-dibromo-2,2'-[1,8-(octanediyldioxy)bis(nitrilomethylidyne)]diphenol, $\left(\mathbf{H}_{2} \mathbf{L}^{2}\right)$ : To a hot ethanolic solution $(10 \mathrm{~mL})$ of 5-bromo-2-hydroxy-benzaldehyde (201.3 mg, $1 \mathrm{mmol}$ ) was added a hot ethanolic solution (10 mL) of 1,8-bis(aminooxy)octane (88.1 mg, $0.50 \mathrm{mmol})$. 


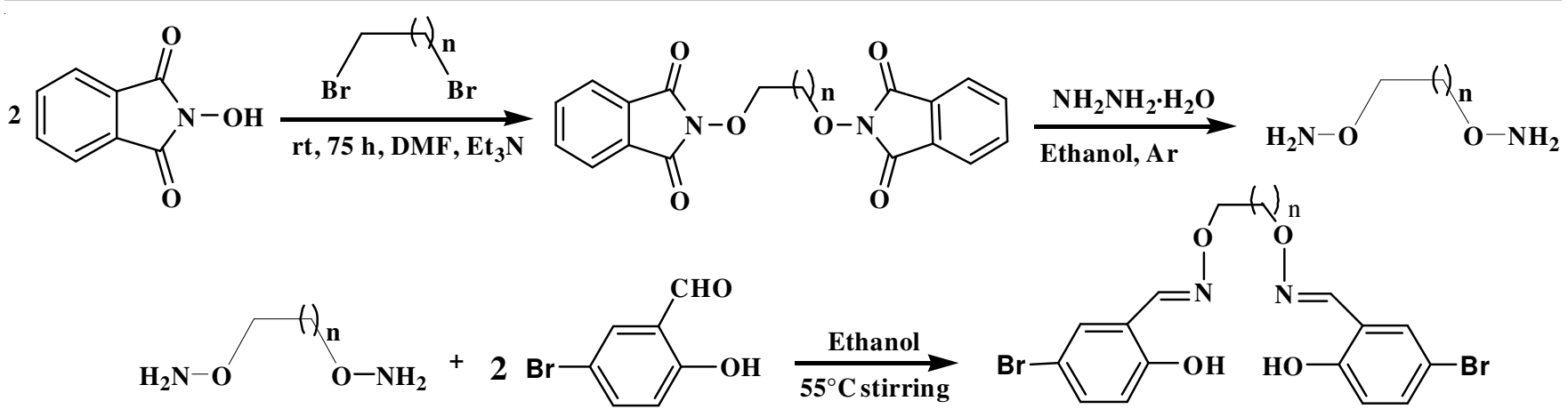

Fig. 1. Synthetic route to Salamo-type bisoxime compounds $\mathbf{H}_{2} \mathbf{L}^{1}-\mathbf{H}_{2} \mathbf{L}^{4}(n=6-9)$

After the solution had been stirred at $60{ }^{\circ} \mathrm{C}$ for $6 \mathrm{~h}$, then cooled to room temperature, the white precipitate was filtered and washed successively with ethanol and $n$-hexane, respectively. The product was purified with recrystallization from ethanol/ $n$-hexane (1/4) and dried under vacuum to obtain $\mathbf{H}_{2} \mathbf{L}^{2}$. Yield (\%): 73.2; m.p.: 389-390 K.

Preparation of 4,4'-dibromo-2,2'-[1,9-(nonanediyldioxy)bis(nitrilomethylidyne)]diphenol, $\left(\mathrm{H}_{2} \mathbf{L}^{3}\right)$ : To a hot ethanol solution $(10 \mathrm{~mL})$ of 5-bromo-2-hydroxy-benzaldehyde (201.3 mg, $1 \mathrm{mmol}$ ) was added a hot ethanol solution $(10 \mathrm{~mL})$ of 1,9-bis(aminooxy)nonane $(95.1 \mathrm{mg}, 0.50 \mathrm{mmol}$ ). After the solution had been stirred at $60{ }^{\circ} \mathrm{C}$ for $6 \mathrm{~h}$, then cooled to room temperature, the white precipitate was filtered and washed successively with ethanol and $n$-hexane, respectively. The product was purified with recrystallization from ethanol $/ n$-hexane (1/4) and dried under vacuum to obtain $\mathbf{H}_{2} \mathbf{L}^{3}$. Yield (\%): 69.1; m.p. 383-384 K.

Preparation of 4,4'-dibromo-2,2'-[1,10-(decanediyldioxy)bis(nitrilomethylidyne)]diphenol, $\left(\mathbf{H}_{2} \mathbf{L}^{4}\right)$ : To a hot ethanol solution $(10 \mathrm{~mL})$ of 5-bromo-2-hydroxy-benzaldehyde (201.3 mg, $1 \mathrm{mmol})$ was added a hot ethanol solution $(10 \mathrm{~mL})$ of 1,10-bis(aminooxy)decane (10.2 mg, $0.50 \mathrm{mmol}$ ). After the solution had been stirred at $60{ }^{\circ} \mathrm{C}$ for $6 \mathrm{~h}$, then cooled to room temperature, the white precipitate was filtered and washed successively with ethanol and $n$-hexane, respectively. The product was purified with recrystallization from ethanol $/ n$ hexane (1/4) and dried under vacuum to obtain $\mathbf{H}_{2} \mathbf{L}^{4}$. Yield (\%): 83.2; m.p.: 373-374 K.

\section{RESULTS AND DISCUSSION}

A series of Salamo-type bisoxime compounds $\mathbf{H}_{2} \mathbf{L}^{1}-\mathbf{H}_{2} \mathbf{L}^{\mathbf{4}}$ have been synthesized with good yields and the compositions are confirmed by elemental analyses, IR, UV-visible spectra and ${ }^{1} \mathrm{H}$ NMR spectroscopy.

Physical and chemistry property: The colour, yields, melting points and elemental analytical results of the synthesized Salamo-type bisoxime compounds $\mathbf{H}_{2} \mathbf{L}^{1}-\mathbf{H}_{2} \mathbf{L}^{4}$ are presented in Table-1. Their compositions agree with the formula. All the compounds are white microcrystalline solid, stable in air and soluble in acetone, chloroform, dichloromethane, tetrahydrofuran, ethyl acetate, DMF and DMSO, insoluble in water, methanol, ethanol, ether, acetonitrile and $n$-hexane.

IR spectra: The most important IR spectra data for $\mathbf{H}_{2} \mathbf{L}^{\mathbf{1}}$ $\mathbf{H}_{2} \mathbf{L}^{4}$ are given in Table-2. In the IR spectra of the title compounds $\mathbf{H}_{2} \mathbf{L}^{1}-\mathbf{H}_{2} \mathbf{L}^{4}$, the characteristic $\mathrm{C}=\mathrm{N}$ stretching bands of the compounds $\mathbf{H}_{2} \mathbf{L}^{1}-\mathbf{H}_{2} \mathbf{L}^{4}$ appear at $1605-1613 \mathrm{~cm}^{-1}$, respectively $^{12}$, indicating that 5-bromo-2-hydroxybenzaldehyde has been condensated with 1,7-bis(aminooxy)heptane, 1,8bis(aminooxy)octane, 1,9-bis(aminooxy)nonane or 1,10bis(aminooxy)decane, respectively and formed novel salamotype compounds. The Ar-O stretching bands occur at 1272$1262 \mathrm{~cm}^{-1}$ as reported for similar bisoxime compounds ${ }^{13}$. The O-H stretching band of the title compounds $\mathbf{H}_{2} \mathbf{L}^{1}-\mathbf{H}_{2} \mathbf{L}^{4}$ appears at $3442-3432 \mathrm{~cm}^{-1}$ region, but this frequency is generally displaced to about $3424 \mathrm{~cm}^{-1}$ because of the internal hydrogen bond $\mathrm{OH} \cdots \mathrm{N}=\mathrm{C}^{14}$.

\begin{tabular}{|c|c|c|c|c|c|c|c|}
\hline \multirow{3}{*}{ Comp. } & \multicolumn{7}{|c|}{$\begin{array}{l}\text { TABLE-1 } \\
\text { COLOUR, YIELDS, MELTING POINTS AND ANALYTICAL DATA } \\
\text { OF BROMO-SUBSTITUTED SALAMO-TYPE BISOXIME COMPOUNDS } \mathbf{H}_{2} \mathbf{L}^{1}-\mathbf{H}_{2} \mathbf{L}^{4}\end{array}$} \\
\hline & \multirow{2}{*}{ Colour } & \multirow{2}{*}{ m.p. (K) } & \multirow{2}{*}{ Yield $(\%)$} & \multirow{2}{*}{ m.f. (m.w.) } & \multicolumn{3}{|c|}{ Elemental analysis (\%): Found (Calcd.) } \\
\hline & & & & & $\mathrm{C}$ & $\mathrm{H}$ & $\mathrm{N}$ \\
\hline $\mathbf{H}_{2} \mathbf{L}^{1}$ & White & $384 \sim 385$ & 82.7 & $\mathrm{C}_{21} \mathrm{H}_{24} \mathrm{Br}_{2} \mathrm{~N}_{2} \mathrm{O}_{4}(446.4)$ & $47,75(47.52)$ & $4.58(4.63)$ & $5.30(5.37)$ \\
\hline $\mathbf{H}_{2} \mathbf{L}^{2}$ & White & $389 \sim 390$ & 73.2 & $\mathrm{C}_{22} \mathrm{H}_{26} \mathrm{Br}_{2} \mathrm{~N}_{2} \mathrm{O}_{4}(460.4)$ & $48.73(48.64)$ & $4.83(4.92)$ & $5.17(5.23)$ \\
\hline $\mathbf{H}_{2} \mathbf{L}^{3}$ & White & $383 \sim 384$ & 69.1 & $\mathrm{C}_{23} \mathrm{H}_{28} \mathrm{Br}_{2} \mathrm{~N}_{2} \mathrm{O}_{4}(474.5)$ & $49.66(49.17)$ & $5.07(5.12)$ & $5.04(5.06)$ \\
\hline $\mathrm{H}_{2} \mathrm{~L}^{4}$ & White & $373 \sim 374$ & 83.2 & $\mathrm{C}_{24} \mathrm{H}_{30} \mathrm{Br}_{2} \mathrm{~N}_{2} \mathrm{O}_{4}(502.5)$ & $50.54(50.03)$ & $5.03(5.26)$ & $4.91(4.93)$ \\
\hline
\end{tabular}

TABLE-2

KEY IR BANDS FOR THE BROMO-SUBSTITUTED SALAMO-TYPE BISOXIME COMPOUNDS $\mathbf{H}_{2} \mathbf{L}^{1} \sim \mathbf{H}_{2} \mathbf{L}^{4}\left(\mathrm{~cm}^{-1}\right)$

\begin{tabular}{ccccccc}
\hline Compound & $v(\mathrm{O}-\mathrm{H})$ & $v\left(\mathrm{CH}_{\text {arom }}\right)$ & $v\left(\mathrm{CH}_{2}\right)$ & $v(\mathrm{C}=\mathrm{N})$ & $v(\mathrm{C}-\mathrm{C})_{\text {benzene ring }}$ & $v(\mathrm{Ar}-\mathrm{O})$ \\
\hline $\mathbf{H}_{2} \mathbf{L}^{\mathbf{1}}$ & 3432 & 3053 & 2946,2887 & 1605 & 1262 \\
$\mathbf{H}_{2} \mathbf{L}^{\mathbf{2}}$ & 3438 & 3058 & 2953,2895 & 1613 & 1479 \\
$\mathbf{H}_{\mathbf{2}} \mathbf{L}^{\mathbf{3}}$ & 3442 & 3056 & 2943,2882 & 1608 & 1271 \\
$\mathbf{H}_{\mathbf{2}} \mathbf{L}^{\mathbf{4}}$ & 3435 & 3051 & 2944,2883 & 1611 & 1272 \\
\hline
\end{tabular}


TABLE-3

UV-VISIBLE SPECTRAL DATA AND ${ }^{1} \mathrm{H}$ NMR DATA FOR THE BROMO-SUBSTITUTED SALAMO-TYPE BISOXIMES $\mathbf{H}_{2} \mathbf{L}^{1}-\mathbf{H}_{2} \mathbf{L}^{4}$

\begin{tabular}{|c|c|c|}
\hline Compound & $\pi-\pi^{*}(\mathrm{~nm})$ & ${ }^{1} \mathrm{H}$ NMR $(400 \mathrm{MHz}, \quad$ DMSO-d 6 , $\delta / p p m)$ \\
\hline $\mathbf{H}_{2} \mathbf{L}^{1}$ & 272,313 & $\begin{array}{l}\left.\text { 2.46-2.55(m, 10H, } \mathrm{CH}_{2}\right), 4.45\left(\mathrm{~s}, 4 \mathrm{H}, \mathrm{CH}_{2}-\mathrm{O}\right), 7.42(\mathrm{~d}, J=2.0 \mathrm{~Hz}, 2 \mathrm{H}, \mathrm{PhH}), 7.56(\mathrm{~d}, J=2.0 \mathrm{~Hz}, 2 \mathrm{H}, \mathrm{PhH}), 7.71(\mathrm{~d}, \\
J=2.2 \mathrm{~Hz}, 2 \mathrm{H}, \mathrm{PhH}), 8.45(\mathrm{~s}, 2 \mathrm{H}, \mathrm{N}=\mathrm{CH}), 9.93(\mathrm{~s}, 2 \mathrm{H}, \mathrm{OH})\end{array}$ \\
\hline $\mathbf{H}_{2} \mathbf{L}^{2}$ & 272,318 & $\begin{array}{l}\text { 2.46-2.54 (m, 12H, CH })_{2}, 4.45\left(\mathrm{~s}, 4 \mathrm{H}, \mathrm{CH}_{2}-\mathrm{O}\right), 7.46(\mathrm{~d}, J=2.0 \mathrm{~Hz}, 2 \mathrm{H}, \mathrm{PhH}), 7.55(\mathrm{~d}, J=2.0 \mathrm{~Hz}, 2 \mathrm{H}, \mathrm{PhH}), 7.71(\mathrm{~d}, \\
J=2.2 \mathrm{~Hz}, 2 \mathrm{H}, \mathrm{PhH}), 8.45(\mathrm{~s}, 2 \mathrm{H}, \mathrm{N}=\mathrm{CH}), 9.96(\mathrm{~s}, 2 \mathrm{H}, \mathrm{OH}) .\end{array}$ \\
\hline $\mathbf{H}_{2} \mathbf{L}^{3}$ & 274,320 & $\begin{array}{l}\text { 2.44-2.53(m, 14H, CH })_{2}, 4.44\left(\mathrm{~s}, 4 \mathrm{H}, \mathrm{CH}_{2}-\mathrm{O}\right), 7.44(\mathrm{~d}, J=2.0 \mathrm{~Hz}, 2 \mathrm{H}, \mathrm{PhH}), 7.54(\mathrm{~d}, J=2.0 \mathrm{~Hz}, 2 \mathrm{H}, \mathrm{PhH}), 7.72(\mathrm{~d}, \\
J=2.2 \mathrm{~Hz}, 2 \mathrm{H}, \mathrm{PhH}), 8.46(\mathrm{~s}, 2 \mathrm{H}, \mathrm{N}=\mathrm{CH}), 9.86(\mathrm{~s}, 2 \mathrm{H}, \mathrm{OH})\end{array}$ \\
\hline $\mathbf{H}_{2} \mathbf{L}^{4}$ & 276,320 & $\begin{array}{l}2.43-2.54\left(\mathrm{~m}, 16 \mathrm{H}, \mathrm{CH}_{2}\right), 4.43\left(\mathrm{~s}, 4 \mathrm{H}, \mathrm{CH}_{2}-\mathrm{O}\right), 7.43(\mathrm{~d}, J=2.0 \mathrm{~Hz}, 2 \mathrm{H}, \mathrm{PhH}), 7.51(\mathrm{~d}, J=2.0 \mathrm{~Hz}, 2 \mathrm{H}, \mathrm{PhH}), 7.71(\mathrm{~d}, \\
J=2.2 \mathrm{~Hz}, 2 \mathrm{H}, \mathrm{PhH}), 8.41(\mathrm{~s}, 2 \mathrm{H}, \mathrm{N}=\mathrm{CH}), 9.79(\mathrm{~s}, 2 \mathrm{H}, \mathrm{OH})\end{array}$ \\
\hline
\end{tabular}

UV-visible spectra: The absorption spectra of $\mathbf{H}_{2} \mathbf{L}^{1}-\mathbf{H}_{2} \mathbf{L}^{4}$ (Table-3), in diluted dichloromethane solution show that the spectra of $\mathbf{H}_{2} \mathbf{L}^{1}-\mathbf{H}_{2} \mathbf{L}^{4}$, are similar to each other.

The compounds $\mathbf{H}_{2} \mathbf{L}^{1}-\mathbf{H}_{2} \mathbf{L}^{4}$ exhibit two intense peaks at around 272 and $320 \mathrm{~nm}$. The former absorption peaks at about $272 \mathrm{~nm}$ can be assigned to the $\pi-\pi^{*}$ transition of the benzene rings, while the latters can be attributed to the intra-ligand $\pi-\pi^{*}$ transition of the $\mathrm{C}=\mathrm{N}$ bonds ${ }^{15}$. It is of note that there was no absorption around $400 \mathrm{~nm}$, which are seen in the corresponding salen derivatives. The absorption peaks are ascribed to the quinoid form of $\mathrm{H}_{2}$ salen $^{16,17}$.

The ${ }^{1} \mathrm{H}$ NMR spectra of the title compounds $\mathbf{H}_{2} \mathbf{L}^{1}-\mathbf{H}_{2} \mathbf{L}^{4}$ in DMSO- $d_{6}$ are shown in Table-3. The ${ }^{1} \mathrm{H}$ NMR spectra showed a singlet at about 8.41-8.46 ppm indicating the existence of oxime bonds ${ }^{16}$.

\section{Conclusion}

In this paper, a series of bromo-substituted Salamo-type compounds $\mathbf{H}_{2} \mathbf{L}^{1}-\mathbf{H}_{2} \mathbf{L}^{4}$ that have two oxime bonds instead of imine bonds have been designed and synthesized by the reaction of 2 equivalents of 5-bromo-2-hydroxybenzaldehyde with 1,7-bis(aminooxy)heptane, 1,8-bis(aminooxy)octane, 1,9-bis(aminooxy)nonane or 1,10-bis(aminooxy)decane under mild conditions, respectively. It is shown that an $O$-alkyl oxime moiety is much more useful to assemble supramolecular systems than a Schiff base moiety. Further investigation on the synthesis and structures of bromo-substituted Salamo-type complexes with transition metal ions, are now in progress.

\section{ACKNOWLEDGEMENTS}

The authors thank The Young Scholars Science Foundation of Lanzhou Jiaotong University and The Fundamental Research Funds for the Gansu Province Universities for financial support of this work.

\section{REFERENCES}

1. C. Meermann, K.W. Törnroos and R. Anwander, Inorg. Chem., 48, 2561 (2009).

2. J. Tisato, F. Refosco and F. Bandoli, Coord. Chem. Rev., 135-136, 325 (1994).

3. S.S. Sundari, A. Dhathathreyan, M. Kanthimathi and B.U. Nair, Langmuir, 13, 4923 (1997).

4. W.K. Dong, G. Wang, S.S. Gong, J.F. Tong, Y.X. Sun and X.H. Gao, Transition Met. Chem., 37, 271 (2012).

5. W.K. Dong, Y.X. Sun, Y.P. Zhang, L. Li, X.N. He and X.L. Tang, Inorg. Chim. Acta, 362, 117 (2009).

6. N.S. Venkataramanan, G. Kuppuraj and S. Rajagopal, Coord. Chem. Rev., 249, 1249 (2005).

7. P.G. Lacroix, Eur. J. Inorg. Chem., 2001, 339 (2001).

8. S.S. Sun, C.L. Stern, S.T. Nguyen and J.T. Hupp, J. Am. Chem. Soc., 126, 6314 (2004).

9. W.K. Dong, X.N. He, H.B. Yan, Z.W. Lv, X. Chen, C.Y. Zhao and X.L. Tang, Polyhedron, 28, 1419 (2009).

10. W.K. Dong and J.G. Duan, J. Coord. Chem., 61, 781 (2008).

11. W.K. Dong, J.H. Feng and X.Q. Yang, Synth. React. Inorg. Met.-Org. Nano-Met. Chem, 37, 189 (2007).

12. W.K. Dong, Y.X. Sun, C.Y. Zhao, X.Y. Dong and L. Xu, Polyhedron, 29, 2087 (2010).

13. T. Ghosh, B. Mondal, T. Ghosh, M. Sutradhar, G. Mukherjee and M. Drew, Inorg. Chim. Acta, 360, 1753 (2007).

14. W.K. Dong, S.J. Xing, Y.X. Sun, L. Zhao, L.Q. Chai and X.H. Gao, J. Coord. Chem., 65, 1212 (2012).

15. J.A. Faniran, K.S. Patel and J.C. Bailar Jr., J. Inorg. Nucl. Chem., 36, 1547 (1974).

16. H.E. Smith, Chem. Rev., 83, 359 (1983).

17. S. Akine, T. Taniguchi and T. Nabeshima, Chem. Lett., 30, 682 (2001). 